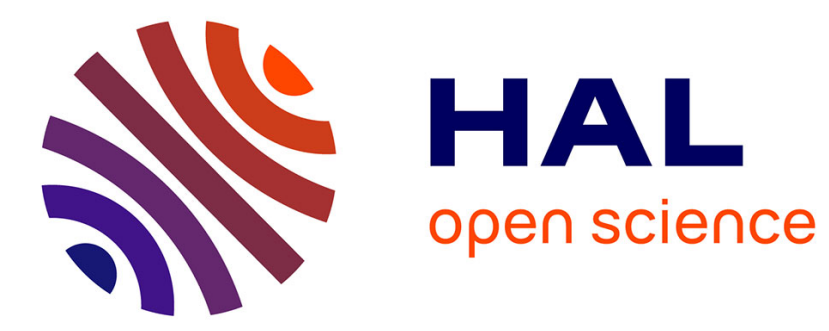

\title{
Comparative study between laboratory and large pilot scales for VOC's removal from gas streams in continuous flow surface discharge plasma
}

\author{
Aymen Amine Assadi, Abdelkrim Bouzaza, Dominique Wolbert
}

\section{To cite this version:}

Aymen Amine Assadi, Abdelkrim Bouzaza, Dominique Wolbert. Comparative study between laboratory and large pilot scales for VOC's removal from gas streams in continuous flow surface discharge plasma. Chemical Engineering Research and Design, 2016, 106, pp.308-314. 10.1016/j.cherd.2015.12.025 . hal-01256845

\section{HAL Id: hal-01256845}

\section{https://hal-univ-rennes1.archives-ouvertes.fr/hal-01256845}

Submitted on 24 Mar 2016

HAL is a multi-disciplinary open access archive for the deposit and dissemination of scientific research documents, whether they are published or not. The documents may come from teaching and research institutions in France or abroad, or from public or private research centers.
L'archive ouverte pluridisciplinaire HAL, est destinée au dépôt et à la diffusion de documents scientifiques de niveau recherche, publiés ou non, émanant des établissements d'enseignement et de recherche français ou étrangers, des laboratoires publics ou privés. 


\section{$1 \quad$ Highlights}

2

3 The removal of isovaleraldehyde by surface plasma discharge was studied

4 Operating parameters are tested at pilot scale with high flow rate

5 The scale-up of plasma reactors were discussed

$6 \quad$ Plasma process was successfully extrapolated at larger scale.

7 


\title{
Comparative study between laboratory and large pilot scales for VOC's removal from gas streams in continuous flow surface discharge plasma
}

\author{
ASSADI Aymen Amine ${ }^{a . b}$, BOUZAZA Abdelkrim ${ }^{a, b^{*}}$, WOLBERT Dominique ${ }^{\mathrm{a}, \mathrm{b}}$, \\ ${ }^{a}$ Laboratoire Sciences Chimiques de Rennes - équipe Chimie et Ingénierie des Procédés, UMR 6226 \\ CNRS, ENSCR-11, allée de Beaulieu, CS 508307-35708 Rennes, France. \\ ${ }^{\mathrm{b}}$ Université Européenne de Bretagne, Rennes-France \\ * Corresponding author. Tel.: +33 2 23238056; fax: +33 223238120. \\ E-mail address: Abdelkrim.bouzaza@ensc-rennes.fr (A. BOUZAZA).
}

Abstract

This work investigated the performance of Isovaleraldehyde (3-methylbutanal) removal from gas streams using continuous flow surface discharge plasma at room temperature. The feasibility of pollutant removal using up-scaled reactor was systematically assessed by monitoring removal efficiency and mineralization at different operational parameters, such as specific energy, air flow rate and inlet concentration. Results show that increasing flow rate lead to improve the removal capacity. For example, when flow rate extends two times, the removal capacity varies from 0.6 to $1.1 \mathrm{~g} . \mathrm{h}^{-1}$. Moreover, when specific energy increased, both removal capacity and mineralization were enhanced. Additionally, a comparison between laboratory and pilot scales using surface discharge plasma system was carried out. A methodology of scaling up the surface discharge plasma system was proposed. In this context, removal capacities were compared for different continuous reactors: two reactors at laboratory scale (planar and cylindrical reactor), and pilot unit. The results suggest that the plasma reactor scale-up for pollutant removal can be feasible.

\section{Keywords}

Scaling-up, Continuous reactor, surface discharge plasma, VOCs treatment, byproducts

\section{Introduction}

Volatile organic compounds (VOCs) had adverse effects on environment and human health. They are emitted from different outdoor sources (motor vehicles, incomplete combustion in industrial processes) (Le Cloirec, 1998) as well as from indoor sources (ADEME, 2005). Various methods have been developed for indoor air cleaning and VOCs 
removal such as thermal and catalytic incineration (Li and Gong, 2010), absorption (Hsu and Lin, 2011), adsorption (Kim and Ahn, 2012), condensation (Tan et al., 2005), biofiltration (Zehraoui et al., 2012), ozonation (Ogata et al., 2010) and photocatalysis (Hussain et al., 2011; Assadi et al., 2012). Although several chemical methods were used or studied for the effective treatment of VOCs, the environmental applications of non-thermal plasma (NTP) started at the beginning of the $\mathbf{X X}^{\text {th }}$ century with the use of plasma-generated ozone for water depollution. Later on, this type of treatment process was successfully developed for air treatment (Khacef et al., 2006).

The most significant advantage of NTP generated in ambient air was the production of highly reactive oxidizing radicals such as $\mathrm{O}^{\circ}$ and $\mathrm{HO}{ }^{\circ}$, and also $\mathrm{O}_{3}$. Such species were produced at room temperature and at low energy cost compared to any alternative methods (Malik et al., 2011; Nunez et al., 1993). As a result, non-thermal plasma could easily break most chemical bonds of molecular pollutants at low temperatures and convert gas pollutants into end-products including $\mathrm{CO}, \mathrm{CO}_{2}, \mathrm{H}_{2} \mathrm{O}$ (Cho et al., 2012). On the other hand, many researches on NTP technologies for processing gases show that NTP is very effective for gas treatment at low VOCs concentrations (Kim, 2004; Hammer, 2014). In fact, our previous research proved that some VOCs in gas streams can be degraded efficiently by surface discharge plasma at laboratory scale pilots with two different geometries (Assadi et al., 2014a).

This present paper was to extend previous research at lab scale (Assadi at al., 2014a; Assadi et al., 2014b) by adding a new investigation about pilot scale of surface plasma application. Moreover, a special attention was given to high flow rate parameter (from 250 to $500 \mathrm{~m}^{3} \cdot \mathrm{h}^{-1}$ ) and its effect on the reactor performance, which is innovative in comparison to the latter studies. Here, isovaleraldehyde (isoval) was chosen since this pollutant was the main molecule detected in the exhaust gases from animal quartering centers (ADEME, 2005). Another goal of the present work is to investigate different reactors scales (laboratory and pilot) in order to see the possibility of the scale-up of the process.

\section{Experimental setup}

The used experimental setup was structured as follows: (i) continuous reactors, (ii) plasma system and (iii) analysis set-up. 


\subsection{Plasma reactors}

\subsubsection{Laboratory reactors}

The experiments were carried out in ambient conditions, i.e. room temperature and pressure. Two lab scale reactors were tested. The first one, planar reactor, consisted of a rectangular cross section $(135 \mathrm{~mm} \times 135 \mathrm{~mm})$ and is $1 \mathrm{~m}$ length. It contained two plates, 4 mm thickness, which were arranged parallel to the length of the reactor and permit to hold up the two electrodes (Fig.1b). The second one, cylindrical reactor, was composed principally of a glass tube (58 $\mathrm{mm}$ id and $100 \mathrm{~cm}$ length). It was covered by a copper grid forming the outer electrode. The glass tube, $4 \mathrm{~mm}$ thickness, acts as the dielectric media. The High Voltage (HV) electrode was a helicoidally wire shaped as a coil spring in close contact with the inner wall of the reactor (Fig. 1a). A detailed description of the geometry of the plasma reactor and electrical measurements was published elsewhere (Guillerm et al., 2014).

Fig1: Scheme and sectional drawing of the cylindrical (a) and planar (b) reactors

\subsubsection{Pilot unit}

This reactor was an air handling unit produced by CIAT (Compagnie Industrielle d'Applications Thermiques- France) with a flow rate capacity up to $5000 \mathrm{~m}^{3} \cdot \mathrm{h}^{-1}$ (Figure2). The unit comprised a pre-filtration box, a cooling bank, an electric heater (box no. 1), a vapor humidifier (box no. 2), a pollutant injection area (box no. 3), an upstream pollution measurement box, a surface plasma treatment system, a downstream concentration measurement box (box no. 4); a fan (box no. 5) and finally an activated carbon filtration (box no. 6). The ventilation box consisted of a medium-pressure centrifugal fan. The used pilot was described in detail in our previous work (Assadi et al., 2014c). 


\subsection{Plasma system}

The experimental set-up for surface discharge production was similar to the planar reactor. In fact, one side of the partition was provided with metallic grid forming the $\mathrm{HV}$ electrode. The total surface area of each lab reactor was $0.18 \mathrm{~m}^{2}$. As seen in figure 3 , the other side was formed of a copper sheet that served as a ground electrode. The two electrodes were separated by a dielectric sheet of glass (thickness $4 \mathrm{~mm}$ ). These elements were tied together and this configuration was reproduced six times forming six parallel channels. The polluted gas flowed through these channels. The details concerning the surface discharge plasma system of the pilot unit were shown in figure 3 .

Figure 3: Photography of Plasma system used in pilot unit

The surface discharge was obtained by submitting the electrodes to a sinusoidal high voltage ranging from 0 to $30 \mathrm{kV}$ (peak to peak) at $50 \mathrm{~Hz}$ frequency. The outer electrode was connected to the ground through a $50 \mathrm{nF}$ of capacity in order to collect the charges transferred through the reactor. The applied voltage $\left(U_{a}\right)$ and high capacitance voltage $\left(\mathbf{U}_{\mathbf{m}}\right)$ were measured by LeCroy high voltage probes and recorded by digital oscilloscope (Lecroy Wave Surfer 24 Xs, $200 \mathrm{MHz}$ ).

The air-isovaleraldehyde gas mixture was prepared by passing synthetic air (Air Liquide) through liquid isovaleraldehyde (Sigma-Aldrich, 97\%). In fact, the pollutant (liquid) was firstly pressurized with air in a stainless steel tank $(500 \mathrm{~mL})$. Then, it was heated, vaporized and mixed with a zero-air flow in an especially designed Bronkhorst vaporization/mixing chamber (CEM). In these conditions, the inlet concentrations ranged from 2 to $10 \mathrm{mg} \cdot \mathrm{m}^{-3}$.

\subsection{Analysis set-up}

The experiment was carried out at room temperature and atmospheric pressure. The temperature and relative humidity were measured by a TESTO sensor. The gases (direct sampling or after concentration) were analysed by means of gas chromatography with a flame 
ionisation detector (FID) or mass spectrometry (MS). $\mathrm{CO}$ and $\mathrm{CO}_{2}$ analysers were used to monitor the carbon monoxide and dioxide. Ozone formed in the plasma reactor was measured by bubbling it through a suitable liquid phase of KI. The analysis system was largely described in previous studies (Assadi et al., 2012, 2013 and 2014a).

\section{Results and discussion}

Experimental parameters were defined as follows: $\left(C_{i n}\right)$ and $\left(C_{\text {out }}\right)$ represented inlet and outlet concentration of pollutant $\left(\mathrm{mg} / \mathrm{m}^{3}\right)$ respectively.

The specific energy (SE) was defined as the energy deposited per unit volume of the gas flow:

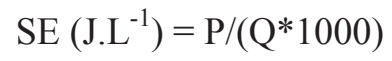

where $\mathrm{P}$ was the input power $(\mathrm{W})$ and $\mathrm{Q}$ denoted the total gas flow rate $\left(\mathrm{m}^{3} \cdot \mathrm{s}^{-1}\right)$.

To evaluate the plasma process, the following parameters are employed:

- The removal capacity (R) which was calculated from:

$$
R=Q \cdot \frac{C_{i n}}{100} \cdot \operatorname{IRE}(\%)
$$

where $\operatorname{IRE}(\%)$ isovaleraldehyde removal was defined as

$$
\operatorname{IRE}(\%)=\frac{C_{\text {in }}-C_{\text {out }}}{C_{\text {in }}} \times 100 \%
$$

- The energy yield $\eta_{E}(e V / m o l e c u l e)=3.21 .10^{3} * P /\left[Q *\left(C_{i n}-C_{\text {out }}\right)\right]$ where 3.21. $10^{3}$ was constant taking account Avogadro's number, molecular weight of Isoval and joule to electron-volt Conversion.

- The selectivities of $\mathrm{CO}$ and $\mathrm{CO}_{2}$ which were defined as:

$$
S_{c o}(\%)=\frac{[\mathrm{co}]}{\left(5 \times[\text { Isoval }]_{\text {comv }}\right)} \times 100
$$

$$
S_{\mathrm{CO}_{2}}(\%)=\frac{\left[\mathrm{CO}_{2}\right]}{\left(5 \times[\mathrm{Isoval}]_{\text {eonv }}\right)} \times 100
$$

where $[\mathrm{CO}]$ and $\left[\mathrm{CO}_{2}\right]$ were respectively the concentrations of carbon monoxide and carbon dioxide detected in the effluent gas as a result of Isoval removal, and [Isoval] conv was the concentration of Isovaleraldehyde converted by plasma surface discharge. 
- Ozone concentration: Ozone was well known to be an inevitable byproduct in a plasma process. It could be formed by the following reaction:

$$
\mathrm{O}^{\circ}+\mathrm{O}_{2}+\mathrm{M} \rightarrow \mathrm{O}_{3}+\mathrm{M}
$$

where $\mathrm{O}^{\circ}$ was atomic oxygen and was generated by $\mathrm{O}_{2}$ dissociation due to its impact with high energy electrons, and $\mathrm{M}$ could be either molecular oxygen or molecular nitrogen (Atkinson et al., 2003). Moreover, several mechanisms occurred when non-thermal plasma was present since plasma produces various species such as high energy electrons, excited molecules or radicals $\left(\mathrm{O}^{\circ}, \mathrm{N}^{*},{ }^{\circ} \mathrm{OH}, \mathrm{O}_{2}{ }^{-}, \mathrm{O}_{3}, \mathrm{NO}_{2}, \mathrm{NO}_{\mathrm{x}}\right.$, etc.). These molecules could interact directly with VOC molecules (Atkinson et al., 2003).

\subsection{Pilot unit efficiency}

The reactor was already being flushed under surface discharge for 1hour when we started sampling for analysis. Indeed, the inlet and outlet gas were then sampled manually. The experiments which were repeated two times; showed a good reproducibility with $\mathbf{5 \%}$ standard deviation. This standard deviation was represented by vertical bars in the experimental results in all figures.

Moreover, the performance of pollutant removal using the pilot unit $\left(500 \mathrm{~m}^{3} \cdot \mathrm{h}^{-1}\right)$ was systematically assessed by monitoring the removal efficiency, the mineralization and ozone formation at different operational parameters, such as specific energy, air flow rate and inlet concentration.

\subsubsection{Removal capacity of Isoval}

The removal capacity of isovaleraldehyde was investigated by studying the effect of specific energy, flowrate and inlet concentration of pollutant (Figure 4.a). Firstly, figure 4.a showed that the increase of flowrate improved the removal capacity. In fact, at flowrate equal to 250 $\mathrm{m}^{3} \cdot \mathrm{h}^{-1}$ and $3 \mathrm{mg} \cdot \mathrm{m}^{-3}$ of inlet concentration, when SE extended six times, the removal capacity increased from 0.2 to $0.45 \mathrm{~g} . \mathrm{h}^{-1}$. This result was similar to those reported for trimethylamine and isovaleric acid at laboratory scale (Assadi et al., 2014a), for toluene (Vandenbroucke et al., 2011), $\mathrm{H}_{2} \mathrm{~S}$ (Chen and Xie, 2013) and for $\mathrm{NO}_{\mathrm{x}}$ (Khacef et al., 2013).. On the other hand, for a selected flow rate, it was interesting to report that experimental results showed an enhanced removal capacity when increasing inlet 
concentration. Similar results were found in previous studies (Assadi et al., 2014a). For diluted effluent, the oxidation rate was directly proportional to the inlet concentration. The degradation occurred to fit a pseudo first-order kinetic. At this specific concentration range, many reactive species remained available for the reaction. On the other hand, the experimental results about the effect of air flow rate (Q) on isovaleraldehyde removal were illustrated in Fig. 4.a. In our case, despite the decrease of residence time, an improvement in the removal capacity was noticed. Indeed, at $\mathrm{SE}=4.5 \mathrm{~J} . \mathrm{L}^{-1}$ and when $\mathrm{Q}$ increased from 250 to $500 \mathrm{~m}^{3} / \mathrm{h}$, removal capacity increased two times. The gas-phase mass transfer rate influenced the treatment capacity by producing a concentration gradient between the bulk and the discharge zone. For instance under transitional conditions, the removal capacity depended on gas-phase mass transfer rate and plasma reaction rate (Assadi et al., 2014d). At higher flow rate, the process become a chemically step controlled. Thus, it could be suggested that the increase of air flow was helpful to the transfer of isovaleraldehyde molecules from bulk to discharge zone (Vandenbroucke et al., 2011).

Figure 4.a: Removal capacity of Isoval and energy yield vs. specific energy at different flow rates and different inlet concentrations using pilot unit.

However, in practice, energy cost $\eta_{E}(\mathrm{eV} /$ molecule) is an important parameter; the variation of this parameter with different operating parameters was shown in figure 4.b. In fact, the energy cost for conversion was higher for lower isoval initial concentrations, exceeding $2.9 \mathrm{keV} / \mathrm{molecule}$ for the lowest concentration investigated $\left(3 \mathrm{mg} / \mathrm{m}^{3}\right)$. On the other hand, we noted that energy cost was flow rate independent because when we increased the flow rate we must increase also the power in order to keep SE constant.

Figure 4.b: Energy yield vs specific energy at different flow rates and different inlet concentrations using pilot unit

\subsubsection{By-products formation}

At pilot scale, the detected by-products were acetone $\left(\mathrm{CH}_{3} \mathrm{COCH}_{3}\right)$, acetic acid $\left(\mathrm{CH}_{3} \mathrm{COOH}\right), \mathrm{CO}$ and $\mathrm{CO}_{2}$. We note that these by-products were similar to those seen at 
lab scale. A possible pathway of Isoval removal was proposed in our previous investigation with cylindrical reactor at lab scale (Assadi et al., 2014e).

\subsubsection{1. $\mathrm{CO}$ and $\mathrm{CO}_{2}$ formation}

When increasing the specific energy, the discharges snatched more electrons from the gasphase inducing a higher concentration of reactive species in the plasma (Fig.5). So, more reactive species were available to induce by-product mineralization. Same results were reported in other studies at laboratory scale (Lee et al., 2014; Zhang et al., 2014; Xiao et al., 2014). It was well known that at laboratory scale, the decrease of flow rate and inlet concentration lead to an increase of mineralization.

Figure 5: Variation of the mineralization vs. specific energy at different inlet concentrations and different flow rates

Fig.6 depicted the effect of specific energy, flow rate and inlet concentration of $\mathrm{CO}$ selectivity. It was interesting to note that whatever the experimental conditions used, experimental results showed that $\mathrm{CO}$ selectivity was globally not dependent upon the inlet concentration and flow rate and it didn't exceed $15 \%$. This effect could be due to tested concentrations interval which was very low. So, the effect of these two parameters was not significant. Previous studies were shown that with surface plasma discharge, the selectivity of CO was widely specific energy dependent (Thevenet et al., 2014; Assadi et al., 2014e).

Figure 6: Variation of the CO selectivity (\%) vs. specific energy at different inlet concentrations and different flow rates.

\subsubsection{Ozone formation}

Fig. 7 showed the variation of $\mathrm{O}_{3}$ concentration with specific energy at different inlet concentration and different flow rates. First of all, it was well known that at laboratory scale, the increase of specific energy leaded to an increase of ozone concentration. The behavior with pilot scale was similar to that was seeing at lab scale. In fact, increasing two times the 
specific energy leaded to an increase of the concentration of formed ozone by $5 \mathrm{ppm}$. Additionally, at $\mathrm{Q}=250 \mathrm{~m}^{3} \cdot \mathrm{h}^{-1}$, the highest ozone concentrations were obtained at low inlet concentration. This suggests, when compared with previous studies, especially with the planar reactor, that the reactive species such as active atomic oxygen and $\mathrm{O}_{3}$ would also be consumed to react with isovaleraldehyde or by-products (Thevenet et al., 2014). Thus, the consumption of active species such as $\mathrm{O}$ could explain the decreasing ozone concentration in the presence of high inlet concentration of Isoval (Reaction 1).

Moreover, ozone increased with the increase of flow rate. In fact, active species usually reacted with VOC present in gas. The decrease of the residence time reduced the active species/VOC contact probability, allowing an important recombination reaction (Reaction1.)

Figure 7: Variation of the ozone vs. specific energy at different inlet concentrations and different flow rates

\subsection{Comparison of reactors}

In the next step of this investigation, we compared results obtained at lab scale with the removal capacity of pilot unit. A methodology was proposed to scale-up surface discharge reactors, employing purely laboratory information, avoiding the need of using adjustable parameters for each different application of the same process. For this purpose, isovaleraldehyde removal was studied previously in a laboratory scale reactor. As explained above, under our experimental conditions, many parameters were kept the same for the two reactors studied: residence time, feed of Isoval (flow rate $\times$ inlet concentration), relative humidity and temperature. Indeed, feed of Isoval and residence times for lab and pilot scale were kept constant and equal to $1.2 \mathrm{~g} \cdot \mathrm{h}^{-1}$ and $0.6 \mathrm{~s}$ respectively $\left(4 \mathrm{~m}^{3} \cdot \mathrm{h}^{-1}\right.$ for the cylindrical reactor, $10 \mathrm{~m}^{3} \cdot \mathrm{h}^{-1}$ for the planar reactor and $250 \mathrm{~m}^{3} \cdot \mathrm{h}^{-1}$ for pilot unit).

Figure 8 showed the removal capacities of Isoval using different scale reactors. The results showed that the removal capacities with Pilot scale were about six times higher than that of the laboratory reactors, regarding to flow rate and plasma surface involved. Moreover, at high value of flow rate, the mass transfer was not a limited step. Thus, previous results and present study confirmed that the scale-up of the surface discharge plasma 
could have been possible from the laboratory reactor study. This study showed that data obtained for surface plasma process at laboratory scale can be used for industrial design.

Figure 8: Different reactors and scales comparison vs. specific energy: Feed of Isoval $=$ $1.2 \mathrm{~g} . \mathrm{h}^{-1}$, residence time $=0.6 \mathrm{~s}$

\section{Conclusion}

The removal of isovaleraldehyde was carried out on surface discharge at pilot scale with high flow rates.

The results showed that the increment's effect of specific energy seemed to be significant on the average removal capacity and on the overall selectivity to $\mathrm{CO}_{2}$. Additionally, the increase of flow rate leaded to improve the removal of pollutant due to enhancement of mass transfer step.

The removal capacities of isovaleraldehyde with three different scale reactors were compared and the feasibility of the scale-up process was demonstrated due to continuity of the experimental results obtained. Thus, the present study confirmed that the scale-up of the surface discharge plasma could have been possible from the laboratory reactor study. Thus, an industrial design of plasma reactor could be possible by using only data lab.

\section{Acknowledgment}

The authors gratefully acknowledged the financial support provided by the French National Research Agency (ANR) for this research work. 
References

ADEME, Pollutions olfactives : origine, législation, analyse, traitement. Ademe, Dunod, Angers, 2005.

Aerts R., Tu X., Van Gaens W., Whitehead J. C.,Bogaerts A., Gas Purification by Nonthermal Plasma: A Case Study of Ethylene, Environmental Science \& Technology. 47 (2013) $6478-6485$

Atkinson R., BaulchD. L., Cox R. A., Crowley J. N., HampsonR. F., Hynes R. G., JenkinM. E., Rossi M. J., TroeJ., Evaluated kinetic and photochemical data for atmospheric chemistry: Part 1 - gas phase reactions of $\mathrm{Ox}, \mathrm{HOx}, \mathrm{NOx}$ and SOx species. Atmospheric chemistry and Physics Discussions 3 (2003) 6179-6699.

Assadi A.A., Bouzaza A., Lemasle M., Wolbert D., Removal of trimethylamine and isovaleric acid from gas streams in a continuous flow surface discharge plasma reactor, Chemical Engineering Research And Design 93 (2015) 640-651.

Assadi A. A., Palau J., Bouzaza A., Penya-Roja J., Martinez-Soria V., Wolbert D., Abatement of 3-methylbutanal and trimethylamine with combined plasma and photocatalysis in a continuous planar reactor, Journal of Photochemistry and Photobiology A: Chemistry 282 (2014 b) 1-8.

Assadi A.A., Bouzaza A., Wolbert D., Petit P., Isovaleraldehyde elimination by $\mathrm{UV} / \mathrm{TiO}_{2}$ photocatalysis: comparative study of the process at different reactors configurations and scales, Environmental Science and Pollution Research 21 (2014 c) 11178-11188

Assadi A. A., Bouzaza A., Merabet S., Wolbert D., Modeling and simulation of VOCs removal by nonthermal plasma discharge with photocatalysis in a continuous reactor: Synergetic effect and mass transfer, Chemical Engineering Journal 258 (2014 d) 119-127.

Assadi A. A, Bouzaza A., Vallet C., Wolbert D., Use of DBD plasma, photocatalysis, and combined DBD plasma/photocatalysis in a continuous annular reactor for isovaleraldehyde elimination - Synergetic effect and byproducts identification, Chemical Engineering Journal 254 (2014 e) 124-132.

Bahri M., Haghighat F., Plasma-Based Indoor Air Cleaning Technologies:The State of the Art-Review, Clean - Soil, Air, Water 42 (2014), 1667-1680

Brandenburg R., Kovacevic V. V., Schmidt M., Basner R., Kettlitz M., Sretenovic G.B.,Obradovic B.M., Kuraica M.M., Weltmann K.-D., Plasma-Based Pollutant Degradation in Gas Streams: Status,Examples and Outlook, Contributions to Plasma Physics, 54 (2014) $202-214$ 
Chen J., XieZh., Removal of $\mathrm{H}_{2} \mathrm{~S}$ in a novel dielectric barrier discharge reactor with photocatalytic electrode and activated carbon fiber. Journal of Hazardous Materials 261 (2013) 38-43

Guillerm M., Assadi A. A., Bouzaza A.,Wolbert D., Removal of gas-phase ammonia and hydrogen sulfide using photocatalysis, nonthermal plasma, and combined plasma and photocatalysis at pilot scale, Environmental Science and Pollution Research, 21 (2014) $13127-13137$

Gumuchiana D., Cavadias S., Dutenc X., Tatouliana M., Da Costa P., Ognier S., Organic pollutants oxidation by needle/plate plasma discharge: On the influence of the gas nature, Chemical Engineering and Processing 82 (2014) 185-192.

Gupta V.K.,Verma N., Removal of volatile organic compounds by cryogenic condensation followed by adsorption. Chemical Engineering Science 57(2002) 2679-2696.

Hammer Th., Atmospheric Pressure Plasma Application for Pollution Control in Industrial Processes, Contributions to Plasma Physics. 54 ( 2014) 187 - 201.

Hussain M., Russo N., Saracco G., Photocatalytic abatement of VOCs by novel optimized $\mathrm{TiO}_{2}$ nanoparticles. Chemical Engineering Journal 166(2011)138-149

Hsu L.J., Lin C.C. Removal of methanol and 1-butanol from binary mixtures by absorption inrotating packed beds with blade packings, Chemical Engineering Journal, 168 (2011)190200

Khacef A.; Cormier J.- M., Pulsed sub-microsecond dielectric barrier discharge treatment of flue gas simulated glass manufacturing industry: Removal of $\mathrm{SO}_{2}$ and $\mathrm{NOx}$, Journal of Physics D: Applied Physics, 39 (2006) 1078-1083

Khacef A., Da Costa P.,Djéga-Mariadassou G., Plasma Assisted Catalyst for NOx Remediation from Lean Gas Exhaust, journal of Engineering and Technology research, 1 (2013) 112-122.

Kim H., Nonthermal Plasma Processing for Air-PollutionControl: A Historical Review, Current Issues, and Future Prospects, Plasma Processes and Polymers. 1 (2004) 91-110.

Kim K.J., Ahn H.G., The effect of pore structure of zeolite on the adsorption of VOCs and theirdesorption properties by microwave heating. Microporous and Mesoporous Materials $152(2012) 78-83$

Le Cloirec P., 1998. Les composés organiques volatils dans l'environnement, Lavoisier, Paris. Lee H., Lee D.-H., Song Y.-H., Choi W. Ch., Park Y.-K., Kim D. H., Synergistic effect of non-thermal plasma-catalysis hybrid system on methane complete oxidation over Pd-based catalysts, Chemical Engineering Journal 259 (2015) 761-770

Li W.B., Gong H., Recent progress in the removal of volatile organic compounds by catalyticcombustion. ActaPhysico-Chimica Sinica 26(2010) 885-894 
Malik M. A., Kolb J. F., Sun Y., Schoenbach K.H., Comparative study of NO removal in surface-plasma and volume-plasma reactorsbased on pulsed corona discharges, Journal of Hazardous Materials 197 (2011) 220-228.

Nunez C.M., Ramsey G.H., Ponder W.H., Abbott J.H., Hamel L.E., Kariher P.H. (1993) Corona destruction:an innovative control technology for VOCs and air toxics. Journal of Air \& Waste Management 43(1993) 242-247.

Ogata A., Saito K., Kim H-H, Sugasawa M., Aritani H., Einaga H., Performance of an Ozone Decomposition Catalyst in Hybrid Plasma Reactors for Volatile Organic Compound Removal, Plasma Chemistry and Plasma Processing 30(2010) 33-42.

Tan S.J., Li L., Xiao Z.Y., Wu Y.T., Zhang Z.B.,Pervaporation of alcoholic beverages: the couplingeffects between ethanol and aroma compounds. Journal of Membrane Science 264(2005) 129-136.

ThevenetF., SivachandiranL., GuaitellaO., BarakatC.,Rousseau A.: Plasma-catalyst coupling for volatileorganic compound removal and indoor airtreatment: a review, Journal of Physics D: Applied Physics 47 (2014) 224011-224022

VandenbrouckeA.M., MorentR., De GeyterN., LeysC., Non-thermal plasmasfor noncatalytic and catalytic VOC abatement, Journal of Hazardous Materials 195 (2011)3054.

Xiao G., XuW., Wu R., Ni M., Du Ch., GaoX., LuoZh., Cen K., Non-Thermal Plasmas for VOCs Abatement, Plasma Chemistry and Plasma Processing 34 (2014) 1033-1065.

Zehraoui A., Hassan A.A., Sorial G.A.Effect of methanol on the biofiltration of n-hexane. Journal of Hazardous Materials 219 (2012) 176-182

Zhang H., Li K., Shu Ch., Lou Z., Sun T., Jia J., Enhancement of styrene removal using a novel double-tube dielectricbarrier discharge (DDBD) reactor, Chemical Engineering Journal 256 (2014) 107-118. 
$429 \quad$ Figures

Fig1: Scheme and sectional drawing of the cylindrical (a) and planar (b) reactors

Figure 2: A functional diagram of pilot unit supplied by CIAT

Figure 3: Photography of Plasma system used in pilot unit

Figure 4.a: Removal capacity of Isoval vs specific energy at different flow rates and different inlet concentrations using pilot unit

Figure 4.b: Energy yield vs specific energy at different flow rates and different inlet concentrations using pilot unit

Figure 5: Variation of the mineralization vs. specific energy at different inlet concentrations and different flow rates

Figure 6: Variation of the CO selectivity (\%) vs. specific energy at different inlet concentrations and different flow rates.

Figure 7: Variation of the ozone vs. specific energy at different inlet concentrations and different flow rates

Figure 8: Different reactors and scales comparison vs. power consumption specific energy: Feed of Isoval $=1.2$ g.h-1, residence time $=0.6 \mathrm{~s}$ 


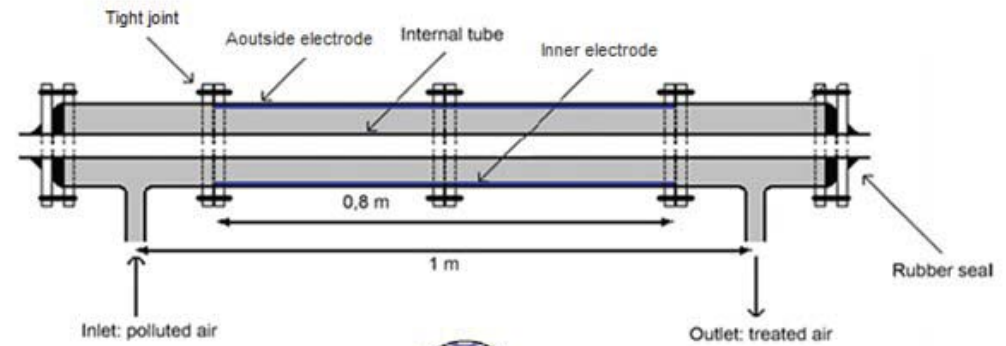

(a)

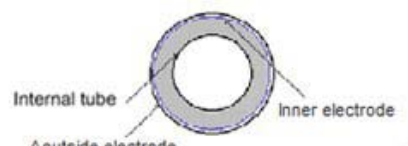

Aoutside electrode

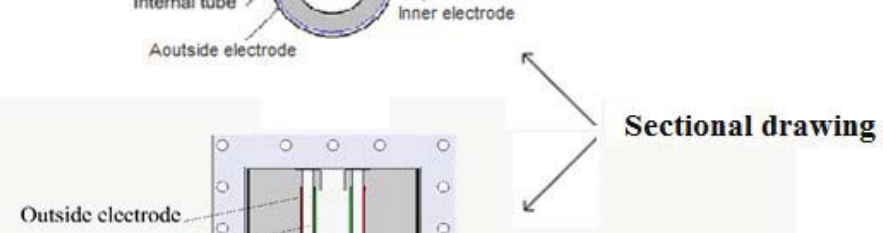

(b)

$$
\text { Glass wall }
$$

Inner electrode

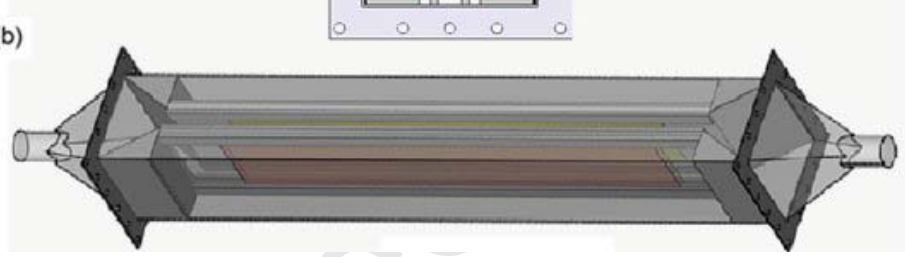




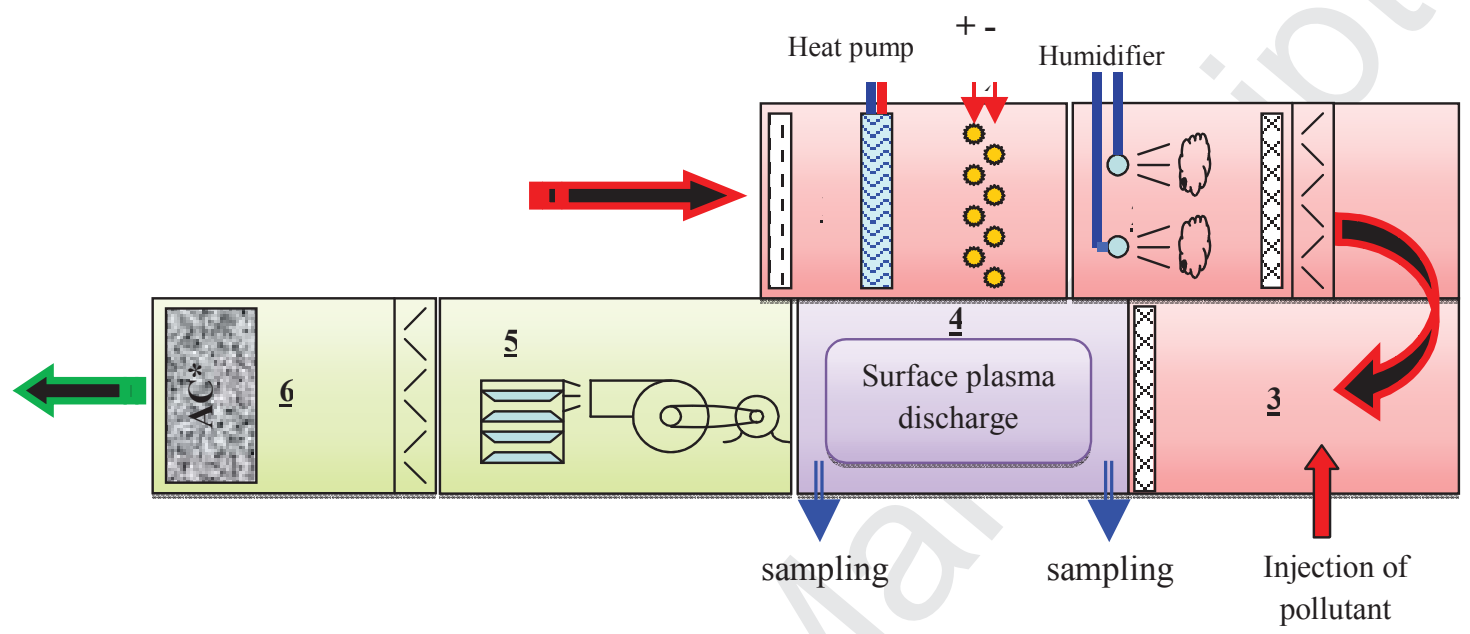

476

477 
490

491

492

493

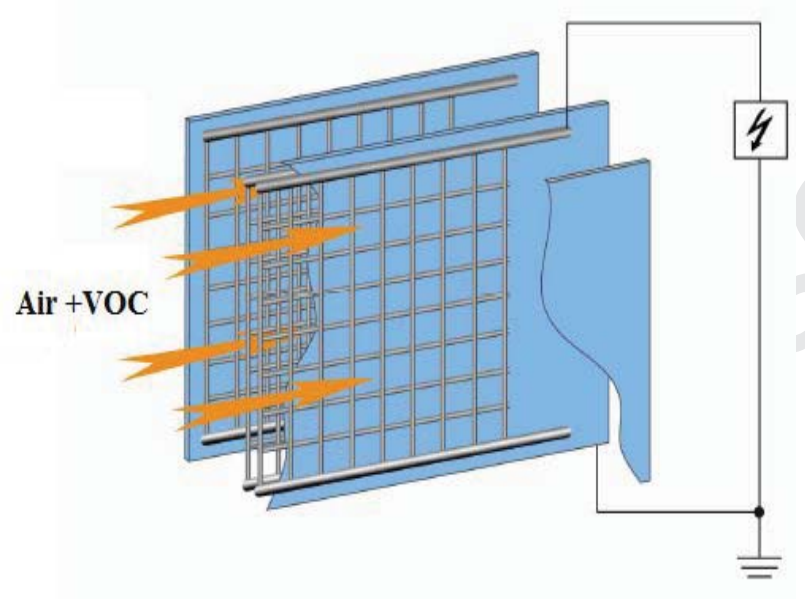

494

495

496

497

498

499

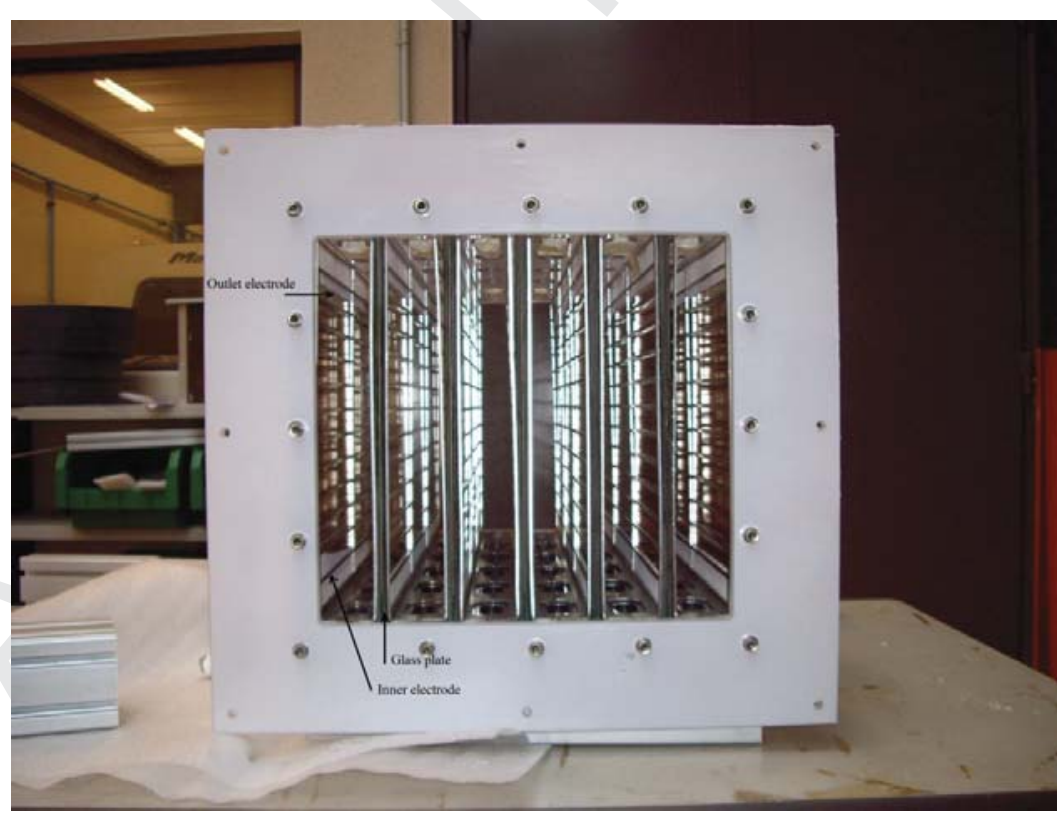

Figure 3: Photography of Plasma system used in pilot unit

Page 18/18 
503

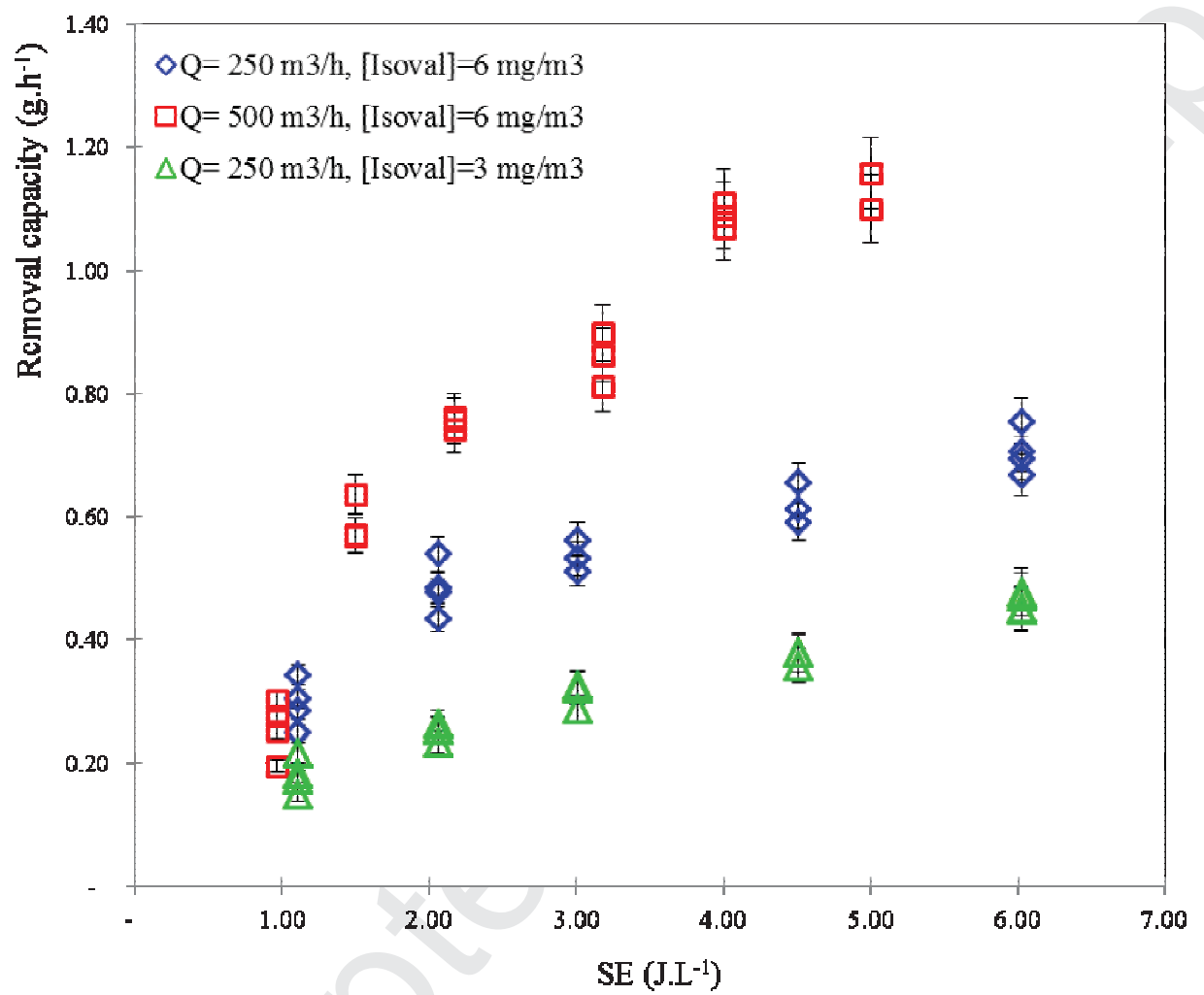

504

505

506

507

508

509

510

511

512

513

514

515

516

Figure 4.a: Removal capacity of Isoval vs specific energy at different flow rates and different inlet concentrations using pilot unit 


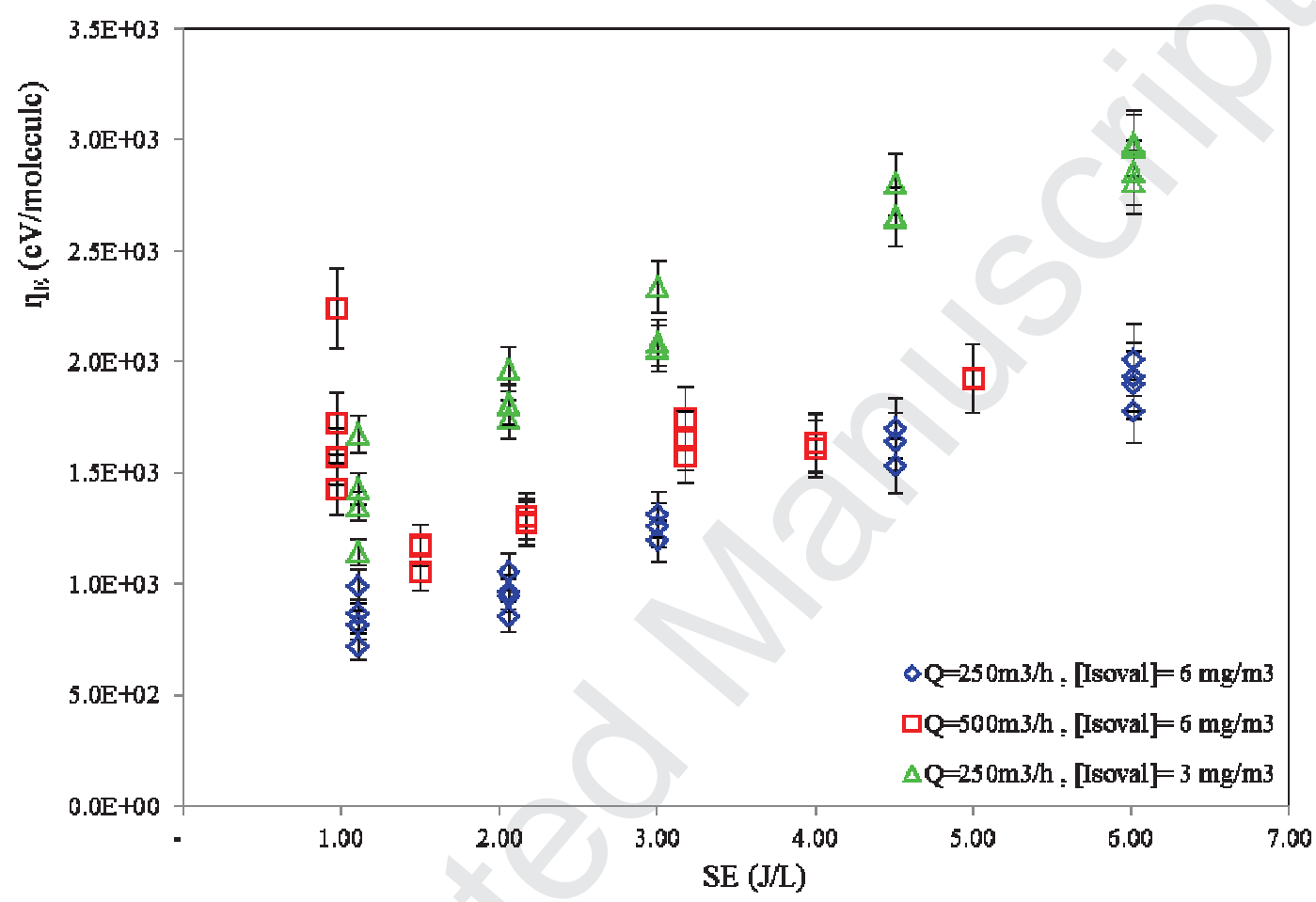

Figure 4.b: Energy yield vs specific energy at different flow rates and different inlet 526 concentrations using pilot unit

527

528

529

530

531

532

533

534

535

536

Page 20/20 
537

538

539

540

541

542

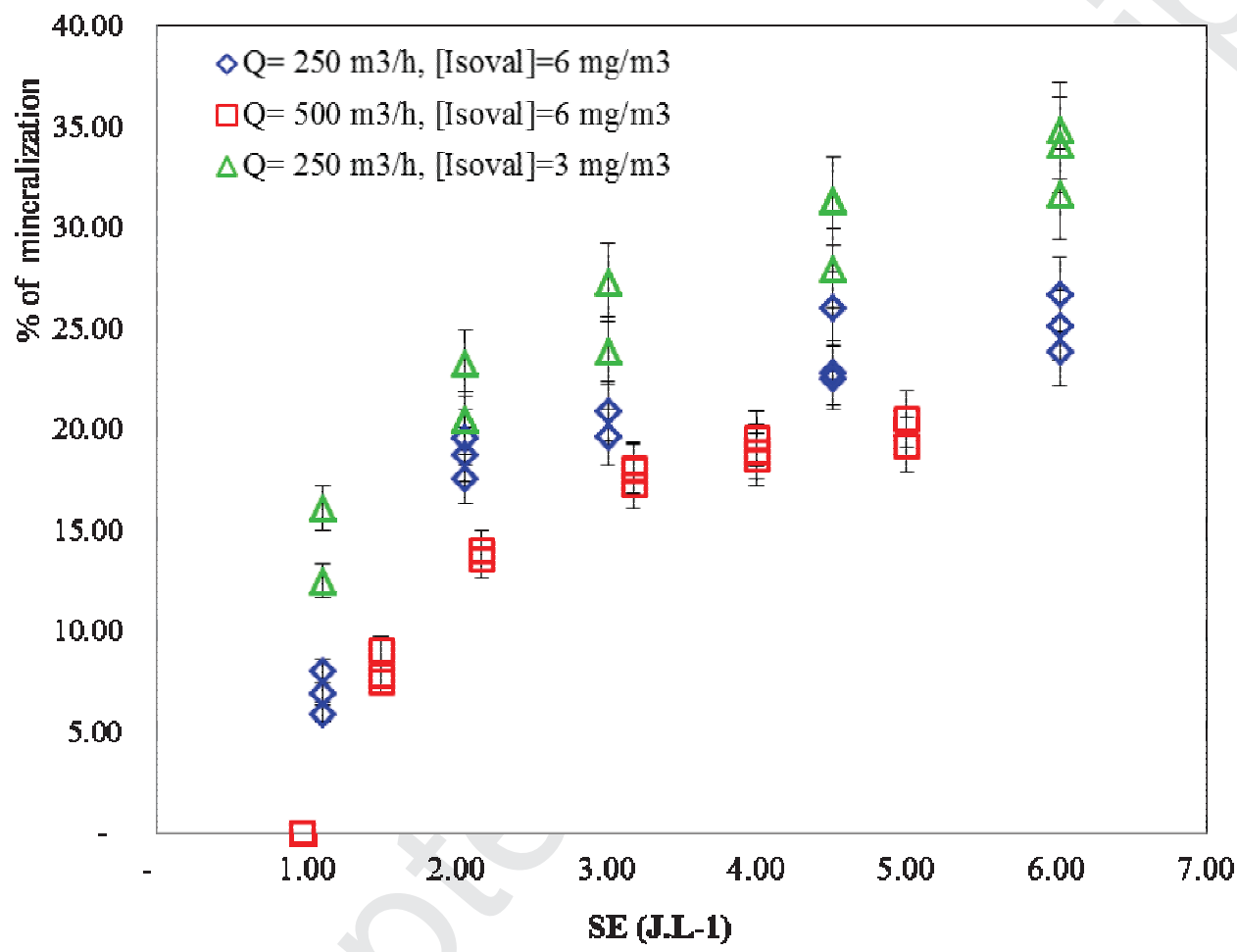

Figure 5: Variation of the mineralization vs. specific energy at different inlet concentrations and different flow rates 


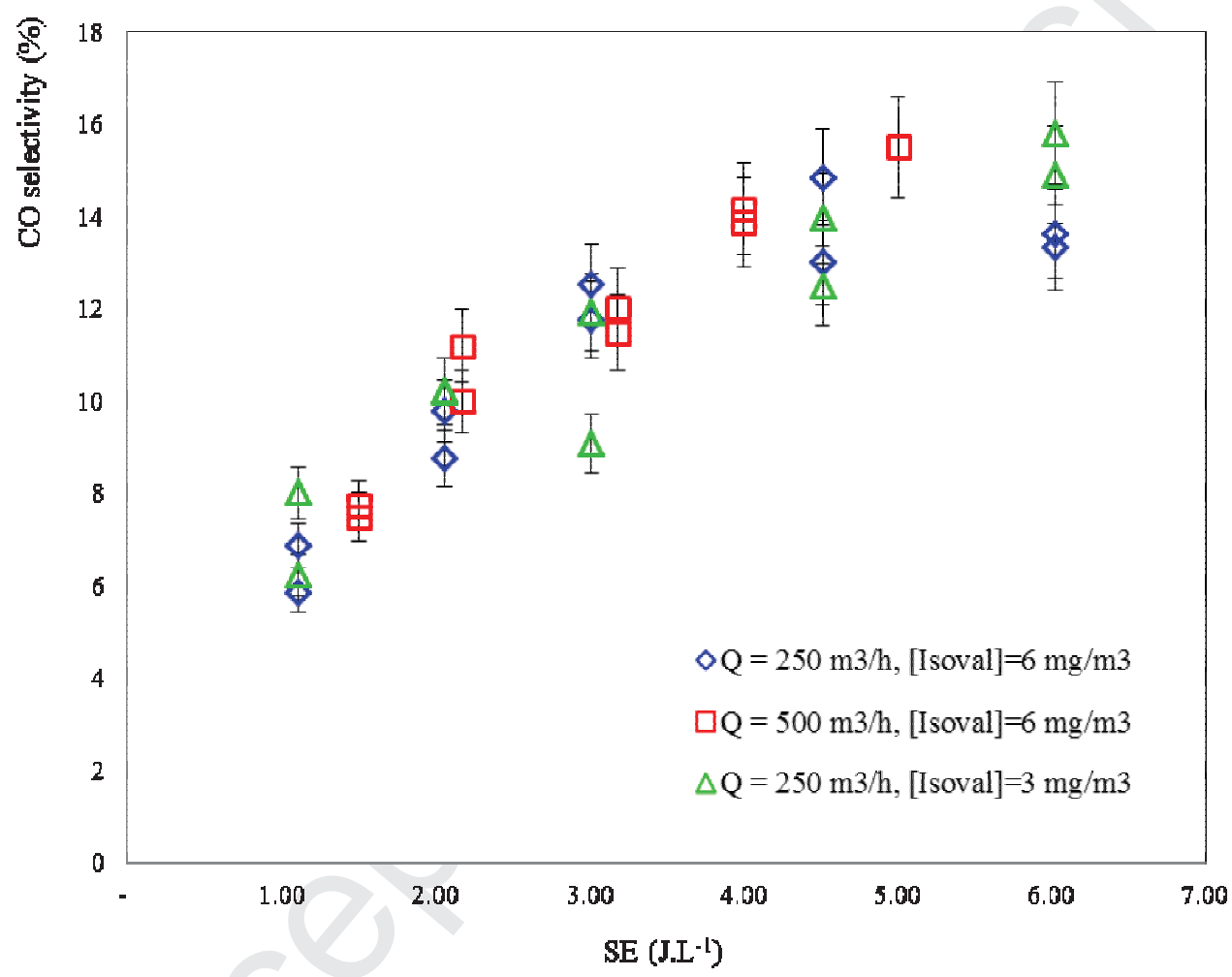
concentrations and different flow rates. 


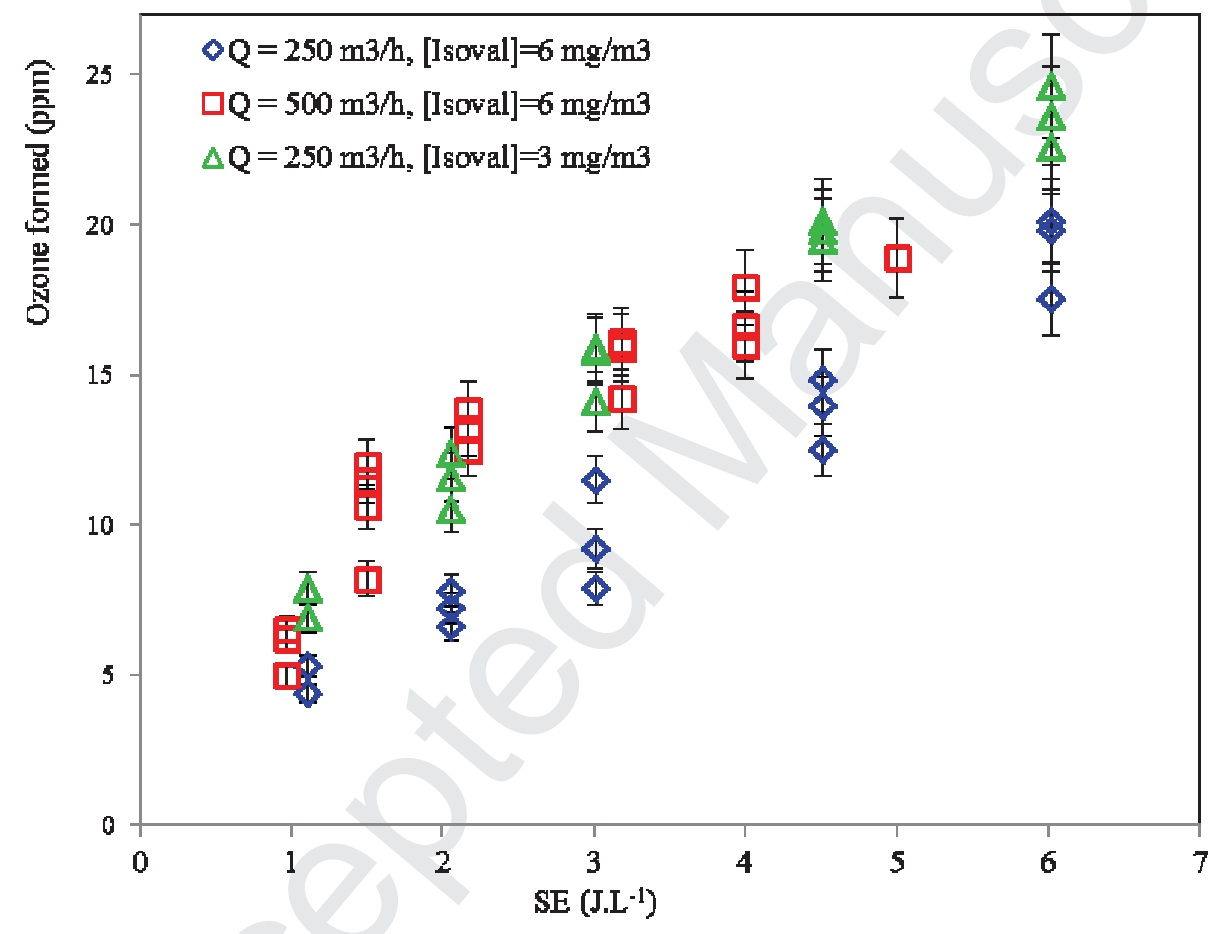

Figure 7: Variation of the ozone vs. specific energy at different inlet concentrations and 


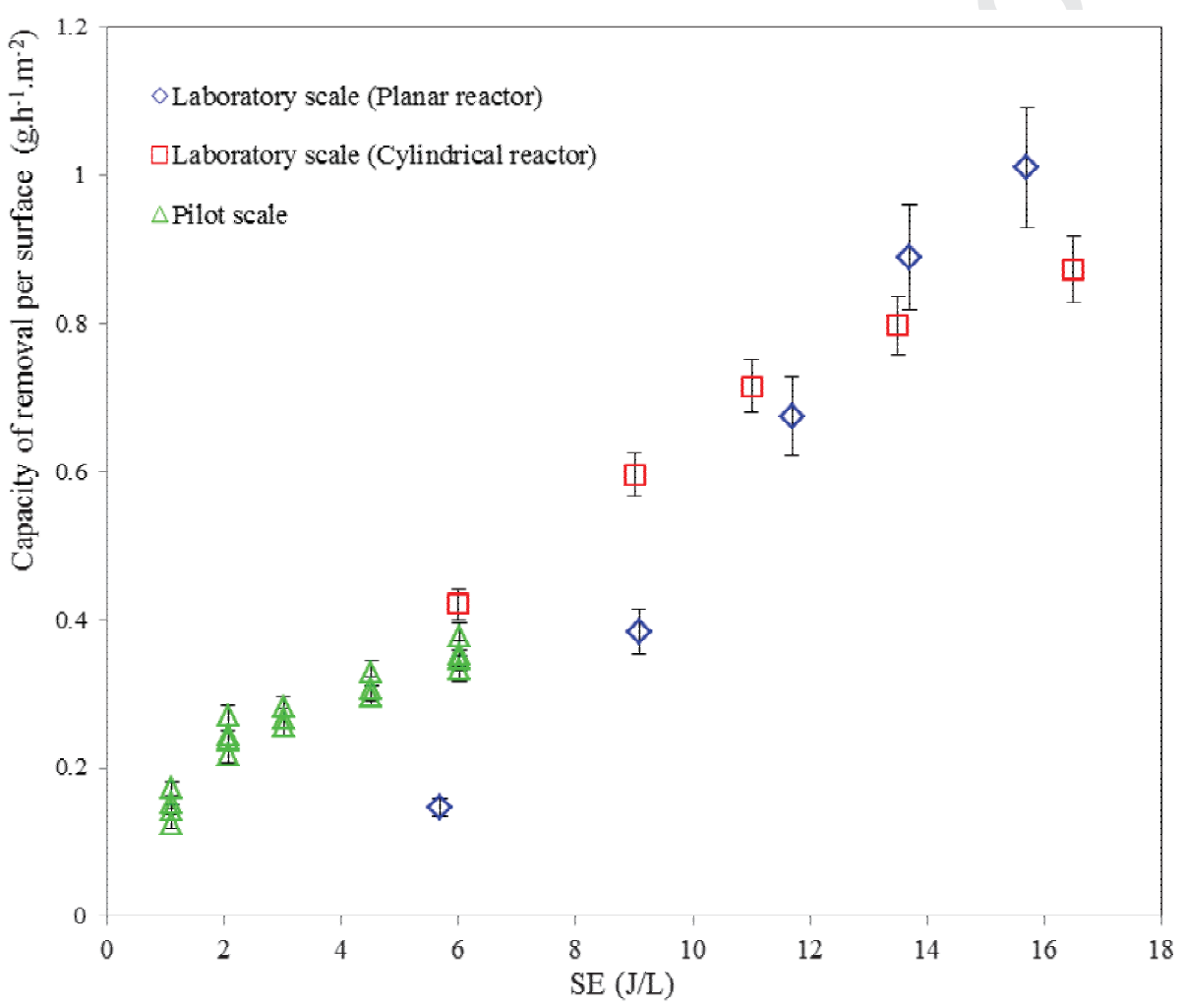

592

Figure 8: Different reactors and scales comparison vs. specific energy: Feed of Isoval = 594 $1.2 \mathrm{~g} \cdot \mathrm{h}^{-1}$, residence time $=0.6 \mathrm{~s}$ 